\title{
Longitudinal follow-up to near final height of auxological changes in girls with idiopathic central precocious puberty treated with gonadotropin- releasing hormone analog and grouped by pretreatment body mass index level
}

Jongho Park, MD', Tae Ho Hwang, MD', Yong-Dae Kim, $\mathrm{PhD}^{3}$, Heon-Seok Han, MD ${ }^{1}$

'Department of Pediatrics, Chungbuk National University Hospital, Chungbuk National University College of Medicine, Cheongju, ${ }^{2}$ Department of Pediatrics, National Medical Center, Seoul, ${ }^{3}$ Department of Preventive Medicine, Chungbuk National University College of Medicine, Cheongju, Korea

Received: 5 July, 2017

Revised: 21 August, 2017

Accepted: 4 September, 2017

Address for correspondence:

Heon-Seok Han, MD

Department of Pediatrics, Chungbuk National University College of Medicine, 1 Chungdae-ro, Seowongu, Cheongju 28644, Korea

Tel: +82-43-269-6370

Fax: +82-43-264-6620

E-mail:hshan@chungbuk.ac.kr

https://orcid.org/0000-0003-00122545
Purpose: Reported changes in body mass index (BMI) in central precocious puberty (CPP) during and after gonadotropin-releasing hormone analog (GnRHa) treatment are inconsistent. We, therefore, investigated auxological parameters in $\mathrm{GnRHa}$ treated girls with idiopathic CPP (ICPP) until attainment of near final height (NFH). Methods: From the medical records of 59 ICPP girls who attained NFH after $\mathrm{GnRHa}$ therapy, auxological changes were compared between overweight $(\mathrm{BMI} \geq 85$ th percentile) and normal-weight (BMl<85th percentile) groups. BMls were changed into standard deviation scores (BMISDSs) for subject chronologic age (BMISDS-CA) and bone age (BMISDS-BA).

Results: The incidence of overweight including obesity was high at the start of therapy (35.6\%). The predicted adult height (PAH) at start of therapy was significantly shorter than the midparental height $(\mathrm{MPH})$, whereas $\mathrm{PAH}$ at end of therapy approached $\mathrm{MPH}$, and NFH was greater than MPH. Height velocity (HV) in the overweight group was higher during GnRHa therapy than that in the normal-weight group, but those in the two groups were not different after therapy until NFH. Both BMISDS-CA and BMISDS-BA increased significantly during therapy, but both BMISDSs decreased significantly after therapy until NFH. At $\mathrm{NFH}$, neither BMISDS was different from that at baseline. In the normal-weight group, both BMISDSs increased during therapy and were maintained until NFH. In the overweight group, neither BMISDS changed during therapy, but there was a decrease after therapy until NFH.

Conclusion: The different patterns of BMISDS change during and after GnRHa therapy until NFH between the 2 groups were related to the different HV during GnRHa therapy.

Keywords: Central precocious puberty, Body mass index, Overweight, Gonadotropinreleasing hormone analog

\section{Introduction}

While several previous studies on the auxological effects of gonadotropin-releasing hormone analog $(\mathrm{GnRHa})$ in central precocious puberty $(\mathrm{CPP})$ have focused on final height outcomes, there are also a few studies that have evaluated treatment-related body weight (BW) changes through changes in body mass index (BMI). However, there have been conflicting results on BMI changes during and after cessation GnRHa therapy. Some authors have stated 
that BMI standard deviation scores (BMISDS) did not change during GnRHa therapy or at final height. ${ }^{1-3)}$ Others reported that BMISDS increased during GnRHa treatment, but returned to pretreatment level at 1-2.5 years after cessation of therapy or at final height. ${ }^{4-6)}$ In addition, there are 2 reports with more extreme results. One showed that an increased BMISDS at baseline continuously decreased during and after treatment until final height. ${ }^{7)}$ The other, from the Spanish registry, showed continuously increasing trend in BMISDS during and after GnRHa therapy and until final height. ${ }^{8)}$ Generally, girls with $\mathrm{CPP}$ are reported to have above average BMI before GnRHa treatment, ${ }^{99}$ and their early pubertal development is positively associated with obesity. ${ }^{10,11}$ Recently, some researchers reported that BMI changes differently during GnRHa therapy according to the subjects' pretreatment BMI level. ${ }^{12,13)}$

In this study, we investigated weight gain during and after GnRHa therapy until near final height (NFH) in girls with idiopathic CPP (ICPP) and compared various auxological parameters in groups based on the subject's pretreatment BMI.

\section{Materials and methods}

\section{Subjects}

We reviewed retrospectively the medical records of girls who were treated with GnRHa between January 2007 and January 2017 and had attained NFH. Subjects with organic brain lesions or systemic diseases that result in disorders in sexual maturation were excluded. All subjects had experienced menarche and had reached a bone age (BA) of more than 13.5 years after GnRHa treatment.

The diagnostic criteria for ICPP were age at breast development less than 8 years, peak luteinizing hormone (LH) level above $5 \mathrm{IU} / \mathrm{L}$ during a standard intravenous $\mathrm{GnRH}$ stimulation test performed before the age of 9 years, BA advancement, and no evidence of a hypothalamo-pituitary lesion as determined by magnetic resonance imaging performed based on clinician's judgment.

\section{Methods}

All subjects underwent GnRHa treatment at dose levels of $75-150 \mu \mathrm{g} / \mathrm{kg}$ of BW with dosage based on subject BW (1.875 mg GnRHa for BW $<20 \mathrm{~kg}, 2.5 \mathrm{mg}$ GnRHa for BW $20-30 \mathrm{~kg}$, and $3.75 \mathrm{mg}$ GnRHa for BW>30 kg). GnRHa was provided every 4 weeks until BA of 11.5-12.0 years. After initiation of GnRHa therapy, the subjects were regularly monitored for height, BW, and sexual maturation rate every 3 months, and a left-hand radiogram was taken every 6 months for BA determination. The criterion for adequate suppression of sexual maturation was met if LH level was <3 IU/L 30-60 minutes after GnRHa injection. BMI was calculated as BW $(\mathrm{kg})$ divided by the square of height $\left(\mathrm{m}^{2}\right)$. BMI values are presented as SDSs based on the 2007 ageand sex-matched Korean standards. Furthermore, BMISDSs were expressed according to chronologic age (CA) and $\mathrm{BA}$ as BMISDS-CA and BMISDS-BA, respectively. BA was assessed by applying the Gleulich-Pyle method ${ }^{14)}$ and the predicted adult height (PAH) was calculated by applying the Bayley-Pinneau method. ${ }^{15)}$ Midparental height (MPH) of the girls in the study was the average height of the parents minus $6.5 \mathrm{~cm}$. NFH was calculated as the PAH at the last follow-up visit after menarche in subjects with a BA greater than 13.5 years.

To assess auxological differences, the subjects were classified into 2 groups, the normal-weight group with a pretreatment BMI less than the 85th percentile, and the overweight group with a pretreatment BMI greater than or equal to the 85 th percentile.

The study protocol was approved by the Institutional Review Board (IRB) of Chungbuk National University Hospital (approval number: 2017-05-015). The need for consent was waived by the IRB as all participants received clinical standard of care only.

\section{Statistical analysis}

Statistical analyses were performed by using IBM SPSS Statistics ver. 23.0 (IBM Corp., Armonk, NY, USA). All data are expressed as mean \pm standard deviation values. The MannWhitney $U$-test was applied to compare differences in numerical variables between groups, while the Wilcoxon signed rank test was applied to compare differences in variables within the groups at each time. A $P$-value of 0.05 or less was considered statistically significant.

\section{Results}

\section{Clinical characteristics in normal-weight and overweight girls with ICPP (Table 1, Fig. 1)}

Among the 59 ICPP girls treated with GnRHa, the mean CA increased from $8.18 \pm 0.91$ years prior to treatment to $10.15 \pm 0.44$ years at the end of treatment. Menarche began at a CA of $11.44 \pm 0.95$ years. The height and PAH of all subjects increased significantly during GnRHa treatment, and after cessation of therapy until NFH. The PAH at start of therapy was significantly shorter than the MPH $(154.60 \pm 5.78$ vs. $158.39 \pm 3.01, P<0.001)$, whereas PAH at the end of therapy $(158.91 \pm 5.45)$ was not different from MPH $(P=0.569)$, and NFH $(160.52 \pm 4.66)$ was greater than the MPH $(P<0.001)$.

Mean values of the parameters for the 2 pretreatment BMIbased groups were not significantly different, except there was a higher BA at the end of therapy in the overweight group than in the normal-weight group (11.30 \pm 0.66 vs. $11.68 \pm 0.33$, $P=0.037$ ). The height velocity (HV) was higher during GnRHa treatment in overweight group than in the normal-weight group (6.74 \pm 1.47 vs. $5.78 \pm 0.89, P=0.010)$, but the HVs in the two groups were not different after cessation of therapy until NFH. Age of menarche and duration of treatment were not different 
Table 1. Clinical characteristics during GnRHa treatment and at near final height of girls with idiopathic central precocious puberty stratified into normal-weight and overweight groups at pretreatment

\begin{tabular}{|c|c|c|c|c|}
\hline Characteristic & Normal $(n=38)$ & Overweight $(n=21)$ & Total $(n=59)$ & $P$-value \\
\hline \multicolumn{5}{|l|}{ At start of GnRHa } \\
\hline$C A(y r)$ & $8.16 \pm 0.98$ & $8.22 \pm 0.82$ & $8.18 \pm 0.91$ & 0.734 \\
\hline$B A(y r)$ & $10.21 \pm 1.11$ & $10.42 \pm 0.95$ & $10.28 \pm 1.05$ & 0.325 \\
\hline Height (cm) & $129.80 \pm 7.04$ & $132.32 \pm 8.68$ & $130.70 \pm 7.69$ & 0.264 \\
\hline $\mathrm{PAH}(\mathrm{cm})$ & $154.17 \pm 5.18$ & $155.49 \pm 6.94$ & $154.60 \pm 5.78$ & 0.481 \\
\hline $\mathrm{MPH}(\mathrm{cm})$ & $158.57 \pm 3.06$ & $158.06 \pm 2.95$ & $158.39 \pm 3.01$ & 0.509 \\
\hline \multicolumn{5}{|l|}{ At stop of GnRHa } \\
\hline$C A(y r)$ & $10.22 \pm 0.44$ & $10.04 \pm 0.41$ & $10.15 \pm 0.44$ & 0.226 \\
\hline $\mathrm{BA}(\mathrm{yr})$ & $11.30 \pm 0.66$ & $11.68 \pm 0.44$ & $11.44 \pm 0.61$ & 0.037 \\
\hline Height $(\mathrm{cm})$ & $141.57 \pm 5.48$ & $144.34 \pm 5.36$ & $142.69 \pm 5.72$ & 0.074 \\
\hline HV (cm/yr) during GnRHa therapy & $5.78 \pm 0.89$ & $6.74 \pm 1.47$ & $6.12 \pm 1.21$ & 0.010 \\
\hline $\mathrm{PAH}(\mathrm{cm})$ & $158.10 \pm 5.19$ & $160.38 \pm 5.73$ & $158.91 \pm 5.45$ & 0.075 \\
\hline Duration of therapy (yr) & $2.06 \pm 1.15$ & $1.82 \pm 0.82$ & $1.97 \pm 1.04$ & 0.481 \\
\hline Age at menarche (yr) & $11.48 \pm 1.11$ & $11.38 \pm 0.55$ & $11.44 \pm 0.95$ & 0.145 \\
\hline \multicolumn{5}{|l|}{ At final follow-up } \\
\hline CA (yr) & $12.73 \pm 0.92$ & $12.27 \pm 0.76$ & $12.57 \pm 0.88$ & 0.093 \\
\hline$B A(y r)$ & $14.51 \pm 1.02$ & $14.56 \pm 0.99$ & $14.53 \pm 1.00$ & 0.891 \\
\hline Height (cm) & $156.37 \pm 5.76$ & $157.44 \pm 6.53$ & $156.75 \pm 6.01$ & 0.296 \\
\hline HV (cm/yr) after therapy until NFH & $6.20 \pm 1.32$ & $6.02 \pm 1.77$ & $6.14 \pm 1.48$ & 0.788 \\
\hline $\mathrm{PAH}(\mathrm{NFH})(\mathrm{cm})$ & $160.14 \pm 4.42$ & $161.21 \pm 5.11$ & $160.52 \pm 4.66$ & 0.315 \\
\hline
\end{tabular}

Values are presented as mean \pm standard deviation.

GnRHa, gonadotropin-releasing hormone analogue; CA, chronologic age; BA, bone age; PAH, predicted adult height; MPH, midparental height; HV, height velocity; NFH, near final height

*Comparison of means between groups by using Mann-Whitney U-test.

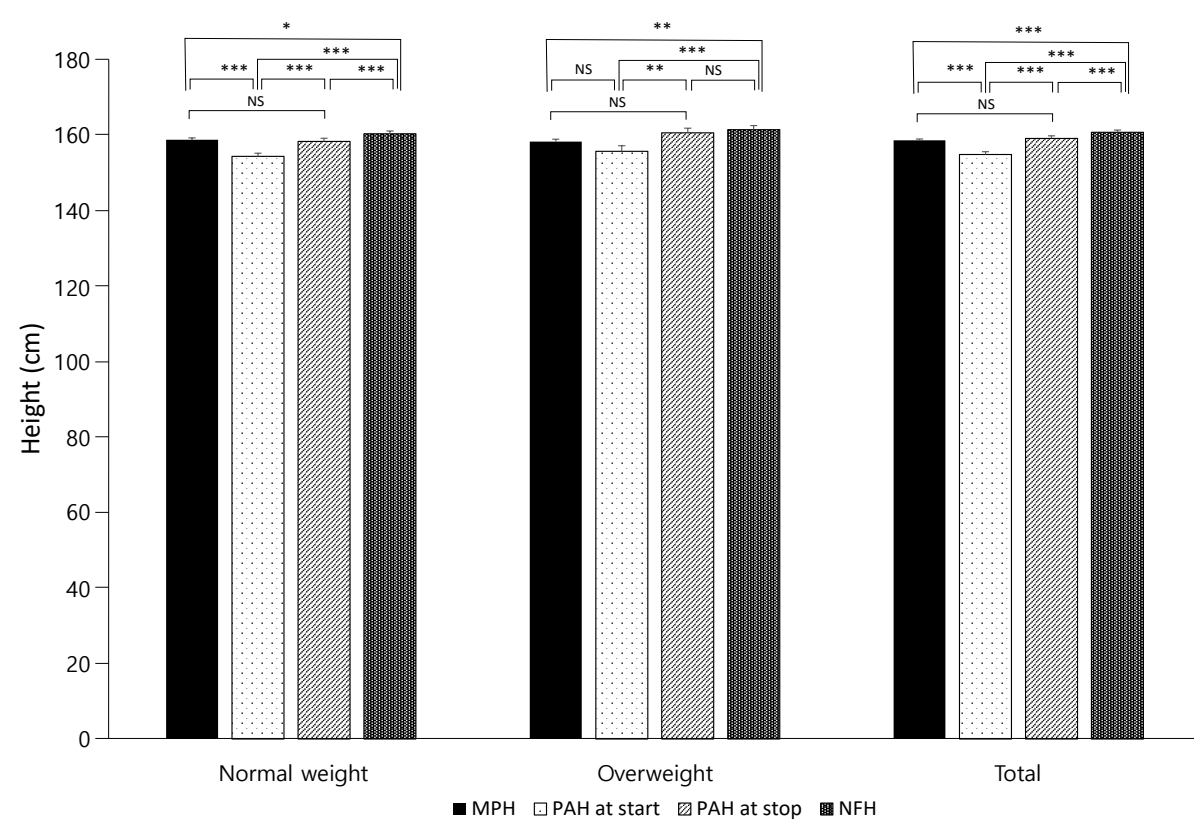

Fig. 1. Comparison in midparental height (MPH) with predicted adult height (PAH) at start and stop of gonadotropinreleasing hormone analogue therapy and at near final height (NFH). In both groups, PAH increased significantly during treatment and PAH at the end of therapy approached to MPH. Data are shown a mean \pm standard error values. NS, not significant. ${ }^{*} P<0.05 .{ }^{* * *} P<0.01$. $^{* * *} P<0.001$. 
between the 2 groups. In the normal-weight group, $\mathrm{PAH}$ was not different from MPH at the end of therapy (158.10 \pm 5.19 vs. $158.57 \pm 3.06, P=0.587)$, but NFH $(160.14 \pm 4.42)$ was greater than MPH $(P=0.010)$. Similarly, in the overweight group, $\mathrm{PAH}$ was not different from MPH at start of therapy (155.49 \pm 6.94 vs. $158.06 \pm 2.95, P=0.164)$, but NFH $(161.21 \pm 5.11)$ was greater than $\mathrm{MPH}(P=0.006)$

Table 2. Changes in BMI and BMISDS according to CA and BA during GnRHa treatment and at last follow-up of near final height in the normal-weight and overweight groups

\begin{tabular}{lcccc}
\hline Variable & $\begin{array}{c}\text { Normal } \\
(n=38)\end{array}$ & $\begin{array}{c}\text { Overweight } \\
(n=21)\end{array}$ & $\begin{array}{c}\text { Total } \\
(n=59)\end{array}$ & P-value $^{*}$ \\
\hline At start of GnRHa & & & & \\
BMI (kg/m $\left.{ }^{2}\right)$ & $16.46 \pm 1.50$ & $20.40 \pm 1.59$ & $17.87 \pm 2.44$ & $<0.001$ \\
BMISDS-CA & $-0.04 \pm 0.72$ & $1.50 \pm 0.39$ & $0.51 \pm 0.96$ & $<0.001$ \\
\hline BMISDS-BA & $-0.51 \pm 0.74$ & $0.93 \pm 0.38$ & $0.00 \pm 0.94$ & $<0.001$ \\
At stop of GnRHa & & & & \\
BMI (kg/m $\left.{ }^{2}\right)$ & $18.40 \pm 1.75$ & $22.25 \pm 1.99$ & $19.77 \pm 2.62$ & $<0.001$ \\
BMISDS-CA & $0.29 \pm 0.65$ & $1.51 \pm 0.50$ & $0.72 \pm 0.85$ & $<0.001$ \\
BMISDS-BA & $0.03 \pm 0.62$ & $1.19 \pm 0.56$ & $0.45 \pm 0.83$ & $<0.001$ \\
At final follow-up & & & & \\
BMI (kg/m $\left.{ }^{2}\right)$ & $19.60 \pm 1.84$ & $22.88 \pm 2.45$ & $20.77 \pm 2.60$ & $<0.001$ \\
BMISDS-CA & $0.16 \pm 0.63$ & $1.19 \pm 0.64$ & $0.52 \pm 0.80$ & $<0.001$ \\
BMISDS-BA & $-0.19 \pm 0.70$ & $0.76 \pm 0.71$ & $0.19 \pm 0.85$ & $<0.001$ \\
\hline
\end{tabular}

Values are presented as mean \pm standard deviation.

$\mathrm{BMI}$, body mass index; SDS, standard deviation score; GnRHa, gonadotropin-releasing hormone analogue; CA, chronologic age; BA, bone age.

${ }^{*}$ Comparison of means between groups by using Mann-Whitney U-test.

\section{Changes of BMl and BMISDS according to $C A$ and $B A$ during $\mathrm{GnRH}$ a treatment and after cessation of $\mathrm{GnRHa}$ at NFH (Table 2)}

Among the 59 ICPP girls in the study, 21 (35.6\%) were in the overweight group. The BMI of all subjects increased during therapy and after the end of therapy at NFH (17.87 \pm 2.44 vs. $19.77 \pm 2.62$ vs. $20.77 \pm 2.670, P<0.001, P=0.001)$. In the normalweight group, BMI continuously increased during therapy, and from the end of therapy to NFH $(16.46 \pm 1.50 \mathrm{vs} .18 .40 \pm 1.75$ vs. $19.60 \pm 1.84, P<0.001, P=0.002)$. In overweight group, BMI increase during treatment $(20.40 \pm 1.59$ vs. $22.25 \pm 1.99, P=0.001)$, but from the end of therapy to NFH, BMI did not change (22.25 \pm 1.99 vs. $22.88 \pm 2.45, P=0.099)$ (Fig. 2).

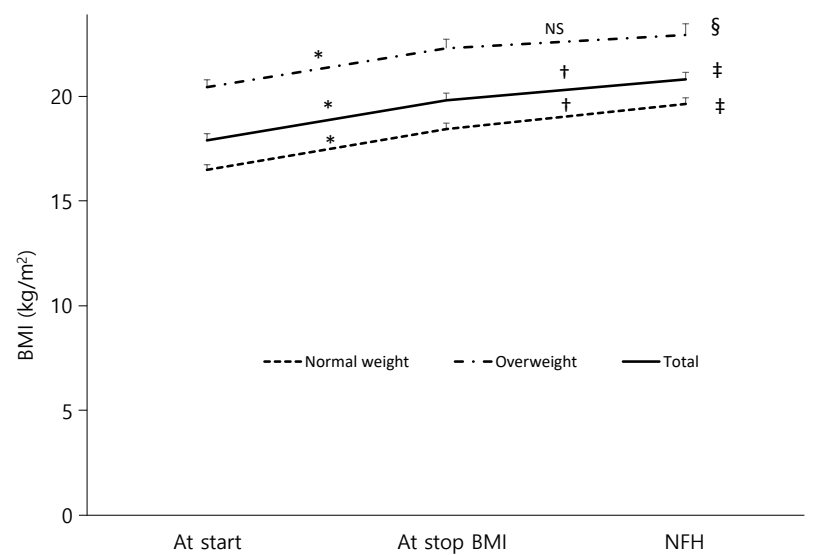

Fig. 2. Changes in body mass index (BMI) at start and at stop of gonadotropinreleasing hormone analogue treatment, and at near final height (NFH) in normalweight and overweight groups. Data are shown as mean \pm standard error values. NS, not significant. ${ }^{*} P<0.001, \mathrm{BMI}$ at start vs. at stop; ${ }^{\dagger} P<0.01, \mathrm{BMI}$ at stop vs. at $\mathrm{NFH} ;{ }^{\ddagger} P<0.001,{ }^{\S} P<0.01, \mathrm{BMl}$ at start vs. at NFH.

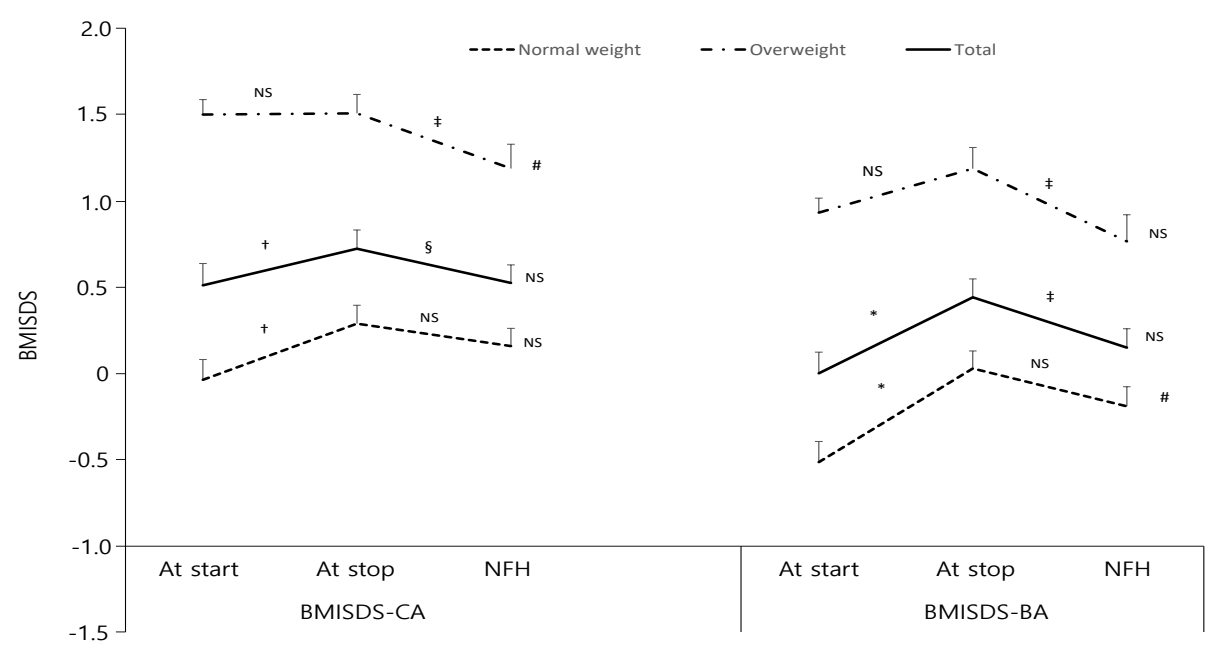

Fig. 3. Changes in body mass index standard deviation score (BMISDS) according to chronologic age (BMISDS-CA) and bone age (BMISDS-BA) at start and at stop of GnRHa treatment and at near final height (NFH) in normal-weight and overweight groups. Data are shown as mean \pm standard error values. ${ }^{*} P<0.001,{ }^{\dagger} P<0.01$, BMISDS at start vs. at stop. ${ }^{\ddagger} P<0.01,{ }^{\S} P<0.05$, BMISDS at stop vs. at NFH. "P $<0.05$, BMISDS at start vs. at NFH. NS, not significant. 
All subjects showed significantly increased BMISDS-CA $(0.51 \pm 0.96$ vs. $0.72 \pm 0.85, P<0.001)$ and BMISDS-BA $(0.00 \pm 0.94$ vs. $0.45 \pm 0.83, P<0.001)$ during GnRHa therapy, and then showed significantly decreased BMISDS-CA $(0.72 \pm 0.85$ vs. $0.52 \pm 0.80, P=0.022)$ and BMISDS-BA $(0.45 \pm 0.83$ vs. $0.19 \pm 0.85$, $P=0.003)$ from the cessation of therapy to NFH. Thus, in all subjects, both the BMISDS-CA and BMISDS-BA at the start point of GnRHa therapy were not different from those at NFH (Fig. 3).

In the normal-weight group, BMISDS-CA showed a significant increase during GnRHa therapy, but no significant change from end of therapy to NFH $(-0.04 \pm 0.72$ vs. $0.29 \pm 0.65$ vs. $0.16 \pm 0.63, P=0.002, P=0.313)$. Likewise BMISDS-BA showed a significant increase during GnRHa therapy, but no significant change at NFH $(-0.51 \pm 0.74$ vs. $0.03 \pm 0.62$ vs. $-0.19 \pm 0.70$, $P<0.001, P=0.109)$. Within the normal-weight group, between the pretreatment and NFH observations, BMISDS-CA showed no significant change $(-0.04 \pm 0.72$ vs. $0.16 \pm 0.63, P=0.116)$, but BMISDS-BA did show a significant increase $(-0.51 \pm 0.74$ vs. $-0.19 \pm 0.70, P=0.029)$. In contrast, in the overweight group, BMISDS-CA showed no significant change during GnRHa therapy, but did decrease significantly from end of therapy to $\mathrm{NFH}(1.50 \pm 0.39$ vs. $1.51 \pm 0.50$ vs. $1.19 \pm 0.64, P=0.741$, $P=0.006$ ). Similarly, BMISDS-BA showed no significant change during GnRHa therapy, but was significantly lower at NFH $(0.93 \pm 0.38$ vs. $1.19 \pm 0.56$ vs. $0.76 \pm 0.71, P=0.054 . P=0.003)$. Within in the overweight group, between the pretreatment and NFH observations, BMISDS-CA showed a significant decrease ( $1.50 \pm 0.39$ vs. $1.19 \pm 0.64, P=0.042$ ), however, BMISDSBA showed no significant difference between those two observations ( $0.93 \pm 0.38$ vs. $0.76 \pm 0.71, P=0.259)$ (Fig. 3 ).

\section{Discussion}

From our study, we obtained the following general results: (1) While clinical characteristics of age, height, PAH, NFH, treatment duration, age at menarche were not significantly different between the normal-weight and overweight groups, the PAH in overweight group approached MPH earlier than it did in the normal-weight group; (2) The HV in overweight group was higher during GnRHa therapy than that in normalweight group, but those in the 2 groups were not different after therapy until NFH; (3) Among all subjects, BMISDS increased during GnRHa therapy, but then decreased at NFH. Thus, baseline BMISDS was not significantly different from BMISDS at NFH; (4) The increase in BMISDS during GnRHa therapy in the normal-weight group did not change further at NFH, while in the overweight group the BMISDS was unchanged during therapy and decreased after cessation of therapy until NFH.

The 21 overweight subjects in our study comprised 35.6\% of the study population and included $11.9 \%$ obese subjects. In Korea, the prevalence of overweight individuals in the general pediatric population was $18.2 \%$, including $8 \%$ with obesity, in 2008. ${ }^{16)}$ Other Korean CPP studies have also reported a high percentage of overweight CPP subjects, ranging from $22.2 \%{ }^{17)}$ to $40.3 \%{ }^{18)}$ Early pubertal development and presence of obesity were reported to be positively correlated in a Chinese study. ${ }^{10)}$ Wagner et al. ${ }^{11)}$ reported that improved nutrition was associated with increased obesity and a secular trend toward earlier puberty. BMI is significantly related to age, especially in girls, and the promotion of sex maturation from stage 1 to stage 2 was statistically related to BMI in a Tukish study. ${ }^{19)}$ The early pubertal onset in obese subjects can be explained by central and peripheral mechanisms. Leptin, an adipose hormone, was suggested as a link between body fat and early puberty via its stimulation of gonadotropin secretion, that is, central pubertal activator. ${ }^{20)}$ McCartney et al. ${ }^{21)}$ reported that peripubertal obesity was associated with marked hyperandrogenemia and hyperinsulinemia before and during early puberty. Decreased sex-hormone binding globulin in obesity increases bioavailability of sex steroids, that is, functioning as a peripheral pubertal activator. ${ }^{22)}$ Also, increased insulin augments LHstimulated ovarian and adrenal steroidogenesis, functioning as both central and peripheral pubertal activators. ${ }^{23)}$ According to a study on growth patterns, obese children, grow faster than normal-weight children during the prepubertal period, but this fast growth is counterbalanced by the attenuated pubertal growth spurt and early pubertal development. Prepubertal fast growth is independent of growth hormone. Not only the increased bioavailability of insulin-like growth factor (IGF)1 due to the decreased IGF binding protein-1, and - 2 from hyperinsulinemia, but also the skeletal growth promoting effect of increased leptin on chondrocyte proliferation and maturation are causes of the prepubertal fast growth rate. Whereas, increased estrogen from aromatization in fat tissue makes bone mature earlier, resulting in similar final height in obese and lean subjects. ${ }^{22)}$ That suggestion might explain our study results showing that, compared to the normal-weight group, the PAH of the overweight group approached MPH earlier.

As a metabolic risk factor, there has been increasing interest in BMI changes occurring in CPP patients before and after GnRHa treatment. In our subjects, BMISDS increased during GnRHa therapy but decreased after cessation of therapy until NFH. This result is similar to those in some other studies that followed subjects until final height, ${ }^{4-6)}$ but it is in contrast to other reports, that showed constant BMISDS during and after GnRHa therapy. ${ }^{1-3)}$ In addition, there are reports of continuously decreasing or continuously increasing BMISDS during as well as after treatment until final height. ${ }^{7,8)}$ Thus, there are broad inconsistencies among reports on the BMISDS changes during and after GnRHa therapy. However, results in reports on the changing patterns of BMISDS during GnRHa treatment after classifying the CPP subjects into BMI-based normal-weight and overweight groups are relatively consistent. As in the present report, most such stratified studies show that the normal-weight group shows increased BMISDS during GnRHa therapy, but, no similar increase in the overweight group. ${ }^{12,17,18,24)}$ Then, what is the cause of different BMISDS changes between the 2 groups? This might be explained by the different height increment 
before and during GnRHa treatment. ${ }^{18)}$ Although our data did not show statistical difference in height and PAH during and after cessation of GnRHa therapy between the 2 groups, those parameters and $\mathrm{HV}$ in overweight group were greater than normal-weight group during GnRHa therapy. Growth hormone independent fast growth in peripubertal obesity is applicable to this phenomenon. This phenomenon in the overweight group made the BMISDS no change during GnRHa therapy. However, there is a paucity of reports on BMISDS change after cessation of GnRHa treatment until final height in Korea. Only one previous Korean report followed-up 35 girls (15 CPP, and 20 early puberty) until final height, and the authors reported no significant changes in BMISDS; BMISDS of 0.54 before GnRHa treatment, 0.50 after treatment, and 0.40 at final height. ${ }^{13)}$ In the present study, we followed 59 ICPP girls until NFH and analyzed them into 2 BMI-based groups.

This study has some limitations. Firstly, the statistical power may be low, because of small sample size. However, this study distinguishes from previous studies that it tracks the BMISDS to the NFH of the subjects. Further large sample sized study seems need. Secondarily, present study did not perform metabolic hormonal analyses, such as, insulin and leptin, which might be useful to elucidate the etiologic approach to the BMISDS changes. In our subjects, BMISDS increased during GnRHa therapy but decreased after cessation of therapy until NFH. The increased BMISDS during treatment seems to be transient phenomenon. Some studies suggested decreased growth hormone and IGF-1 might play a role in the increment of fat mass and decrease in lean body mass. ${ }^{3,25)}$ Traggiai et al. ${ }^{6}$ compared 29 ICPP girls with 45 healthy girls with normal onset puberty matched for age and pubertal stage, and they found increasing BMISDS in the patients at the end of therapy and a complete recovery after 2.5 years of the end of therapy. They suggested the difference was due to the GnRHa treatment.

In conclusion, the percentage of subjects that were overweight was high in girls with ICPP, and the auxological parameters of growth were not different between the normal-weight and overweight groups both during and after cessation of GnRHa therapy. Compared to the normal-weight group and based on $\mathrm{PAH}$, the overweight group attained MPH more quickly. Overall the BMISDS increased during GnRHa therapy but decreased after cessation of therapy until NFH. Therefore, increased BMISDS during treatment is transient phenomenon caused by GnRHa treatment. The patterns of change in BMISDSs from pretreatment to end of GnRHa therapy and from cessation of treatment to NFH were different between the 2 groups, and this might be explained by different growth velocity of the 2 groups during GnRHa treatment.

\section{Conflict of interest}

No potential conflict of interest relevant to this article was reported.

\section{References}

1. Palmert MR, Mansfield MJ, Crowley WF Jr, Crigler JF Jr, Crawford JD, Boepple PA. Is obesity an outcome of gonadotropin-releasing hormone agonist administration? Analysis of growth and body composition in 110 patients with central precocious puberty. J Clin Endocrinol Metab 1999;84:4480-8

2. Heger S, Partsch CJ, Sippell WG. Long-term outcome after depot gonadotropin-releasing hormone agonist treatment of central precocious puberty: final height, body proportions, body composition, bone mineral density, and reproductive function. J Clin Endocrinol Metab 1999;84:4583-90.

3. Pasquino AM, Pucarelli I, Accardo F, Demiraj V, Segni M, Di Nardo R. Long-term observation of 87 girls with idiopathic central precocious puberty treated with gonadotropinreleasing hormone analogs: impact on adult height, body mass index, bone mineral content, and reproductive function. J Clin Endocrinol Metab 2008;93:190-5.

4. Paterson WF, McNeill E, Young D, Donaldson MD. Auxological outcome and time to menarche following longacting goserelin therapy in girls with central precocious or early puberty. Clin Endocrinol (Oxf) 2004;61:626-34.

5. van der Sluis IM, Boot AM, Krenning EP, Drop SL, de Muinck Keizer-Schrama SM. Longitudinal follow-up of bone density and body composition in children with precocious or early puberty before, during and after cessation of GnRH agonist therapy. J Clin Endocrinol Metab 2002;87:506-12.

6. Traggiai C, Perucchin PP, Zerbini K, Gastaldi R, De Biasio P, Lorini R. Outcome after depot gonadotrophinreleasing hormone agonist treatment for central precocious puberty: effects on body mass index and final height. Eur J Endocrinol 2005; 153:463-4.

7. Arrigo T, De Luca F, Antoniazzi F, Galluzzi F, Segni M, Rosano M, et al. Reduction of baseline body mass index under gonadotropin-suppressive therapy in girls with idiopathic precocious puberty. Eur J Endocrinol 2004;150:533-7.

8. Corripio R, Soriano-Guillén L, Herrero FJ, Cañete R, Castro-Feijoó L, Escribano A, et al. Changes in body mass index in girls with idiopathic central precocious puberty under gonadotropin-releasing hormone analogue therapy: The Spanish Registry. Horm Res Paediatr 2016;86:154-60.

9. Carel JC, Eugster EA, Rogol A, Ghizzoni L, Palmert MR; ESPE-LWPES GnRH Analogs Consensus Conference Group, et al. Consensus statement on the use of gonadotropin-releasing hormone analogs in children. Pediatrics 2009;123:e752-62.

10. Chen C, Zhang Y, Sun W, Chen Y, Jiang Y, Song Y, et al. Investigating the relationship between precocious puberty and obesity: a cross-sectional study in Shanghai, China. BMJ Open 2017;7:e014004.

11. Wagner IV, Sabin MA, Pfäffle RW, Hiemisch A, Sergeyev 
E, Körner A, et al. Effects of obesity on human sexual development. Nat Rev Endocrinol 2012;8:246-54.

12. Wolters B, Lass N, Reinehr T. Treatment with gonadotropinreleasing hormone analogues: different impact on body weight in normal-weight and overweight children. Horm Res Paediatr 2012;78:304-11.

13. Lee HS, Yoon JS, Roh JK, Hwang JS. Changes in body mass index during gonadotropin-releasing hormone agonist treatment for central precocious puberty and early puberty. Endocrine 2016;54:497-503.

14. Greulich WW, Pyle SI. Radiographic atlas of skeletal development of the hand and wrist. 2nd ed. Redwood City (CA): Stanford University Press, 1959.

15. Bayley N, Pinneau SR. Tables for predicting adult height from skeletal age: revised for use with the Greulich-Pyle hand standards. J Pediatr 1952;40:423-41.

16. Oh K, Jang MJ, Lee NY, Moon JS, Lee CG, Yoo MH, et al. Prevalence and trends in obesity among Korean children and adolescents in 1997 and 2005. Korean J Pediatr 2008;51:950-5.

17. Yoon JY, Kang MJ, Kim SY, Seo JY, Yang SW, Lee YA, et al. The relationship between initial body mass index and body mass index after one year of gonadotropin-releasing hormone agonist therapy in idiopathic true precocious puberty girls. J Korean Soc Pediatr Endocrinol 2011;16:16571.

18. Yang WJ, Ko KH, Lee KH, Hwang IT, Oh YJ. The different effects of gonadotropin-releasing hormone agonist therapy on body mass index and growth between normal-weight and overweight girls with central precocious puberty. Ann Pediatr Endocrinol Metab 2017;22:49-54.

19. Kanbur NO, Derman O, Kinik E. Prevalence of obesity in adolescents and the impact of sexual maturation stage on body mass index in obese adolescents. Int J Adolesc Med Health 2002;14:61-5.

20. Kaplowitz PB. Link between body fat and the timing of puberty. Pediatrics 2008;121 Suppl 3:S208-17.

21. McCartney CR, Blank SK, Prendergast KA, Chhabra S, Eagleson CA, Helm KD, et al. Obesity and sex steroid changes across puberty: evidence for marked hyperandrogenemia in pre- and early pubertal obese girls. J Clin Endocrinol Metab 2007;92:430-6.

22. De Leonibus C, Marcovecchio ML, Chiarelli F. Update on statural growth and pubertal development in obese children. Pediatr Rep 2012;4:e35.

23. Poretsky L, Cataldo NA, Rosenwaks Z, Giudice LC. The insulin-related ovarian regulatory system in health and disease. Endocr Rev 1999;20:535-82.

24. Park J, Kim JH. Change in body mass index and insulin resistance after 1-year treatment with gonadotropinreleasing hormone agonists in girls with central precocious puberty. Ann Pediatr Endocrinol Metab 2017;22:27-35.

25. Kamp GA, Manasco PK, Barnes KM, Jones J, Rose SR, Hill SC, et al. Low growth hormone levels are related to increased body mass index and do not reflect impaired growth in luteinizing hormone-releasing hormone agonisttreated children with precocious puberty. J Clin Endocrinol Metab 1991;72:301-7. 